\title{
Mobile learning in nursing education: catering for students and teachers' needs
}

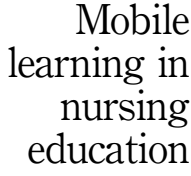

\begin{abstract}
Purpose - The purpose of this paper is to evaluate the implementation of mobile learning in a nursing course at The Open University of Hong Kong, and identify the potentials of, and constraints on, introducing mobile technologies in the instructional design of nursing education. The paper also considers the pedagogical implications of the expansion of mobile learning in the field of nursing.

Design/methodology/approach - The research adopts a qualitative approach to obtain the students' and teacher's experiences, opinions, and expectations on mobile learning. Two focus groups with 20 student participants were conducted and an in-depth interview with the course teacher was arranged. The Framework for the Rational Analysis of Mobile Education (FRAME) model was used as the research framework to support data collection and analysis.

Findings - The aspects of device usability, interaction learning, and social technology as suggested in the FRAME model were partly fulfilled in the study. Mobile technology enhanced the portability and accessibility of learning information, and networking tools facilitated interaction among students and between students and the teacher. However, the readability of text was limited due to constraints on the user interface and screen size, and concerns over the reliability of learning content were also raised, given the abundance of unfiltered online information. The difficulty in updating the content of multimedia materials and sourcing videos of an appropriate level, together with the problem of device networking, also limited the usefulness of mobile learning. Attention should also be paid to the perceptual differences between students and the teacher on the nature and functions of mobile learning.

Originality/value - This empirical study provides a detailed evaluation of the delivery of mobile learning in a nursing course. The findings reveal the strengths and limitations of using mobile technologies to support the nursing education.
\end{abstract}

Keywords Learning and teaching, Mobile learning, User needs, Nursing education

Paper type Research paper

\section{Introduction}

Mobile learning has been playing an increasingly crucial role in education, allowing learning to take place beyond geographical barriers and time constraints. It supports learners who are studying "on the move" to access learning materials in various contexts, with different cultural and environmental cues necessary for understanding the learning contents (Evans, 2008; Koole, 2009). It also facilitates social interaction among learners and teachers through mobile applications such as text messaging or student response tools (Uzunboylu and Ozdamli, 2011).

Nursing education is one of the areas where mobile learning is highly desirable, as it emphasises the acquisition of conceptual knowledge and practical skills in different learning

(C) Kam Cheong Li, Linda Yin-King Lee, Suet-Lai Wong, Ivy Sui-Yu Yau and Billy Tak Ming Wong. Published in the Asian Association of Open Universities Journal. Published by Emerald Publishing Limited. This article is published under the Creative Commons Attribution (CC BY 4.0) licence. Anyone may reproduce, distribute, translate and create derivative works of this article (for both commercial and noncommercial purposes), subject to full attribution to the original publication and authors. The full terms of this licence may be seen at http://creativecommons.org/licences/by/4.0/legalcode

The work described in this paper was substantially supported by a grant from the Research Grants Council of the Hong Kong Special Administrative Region, China (UGC/FDS16/H10/14).
Received 12 April 2017 Revised 1 December 2017 Accepted 4 December 2017 
AAOUJ 12,2

contexts, such as the classroom, laboratory, and clinical settings. The use of mobile devices in nursing education provides just-in-time information, and supports situated, experiential, and contextualised learning (Kukulska-Hulme and Traxler, 2005).

This study focusses on the practice of mobile learning in nursing education at The Open University of Hong Kong. The university has been using mobile and wireless technologies for supporting clinical education since 2004 to remove the physical barriers associated with classroom learning (Lee and Tsang, 2006). Its nursing programmes have been making the use of mobile devices in clinical practicums to help students access the learning materials anywhere and anytime to complete their clinical assessment. Based on the success of this experience, the university has been extending the mobile learning practice to the classroom setting in nursing courses (Li et al., 2015). A mobile app has been developed to provide features which enhance students' learning and class interaction, and support class administration.

This paper aims to synthesise the views and suggestions of nursing students and their teacher when engaged in mobile learning. Based on Koole's (2009) Framework for the Rational Analysis of Mobile Education (FRAME) model, this study evaluates the potency of mobile learning in nursing education with a specific focus on the aspects of device usability, interaction learning, and social technology. The research collected first hand the mobile learning experience of the participants, which is of significant value in analysing the potentials and constraints in the design and delivery of mobile learning (Baker et al., 2014). A better integration of mobile technologies with the characteristics of the discipline is suggested to achieve a higher level of learning and teaching effectiveness.

\section{Literature review}

\section{Mobile learning in nursing education}

Mobile learning refers to the learning across physical and virtual contexts supported by mobile technologies (Koole, 2009). It has been described as "spontaneous, personal, informal, contextual, portable, ubiquitous, and pervasive" (Kukulska-Hulme, 2005, p. 2), and responds to the changing concepts of space, community, and discourse produced by technological transformations (Traxler, 2009).

The effectiveness of mobile learning is dependent on various factors. Previous studies have suggested that the design, functionality, and usability of the devices, such as screen size and readability, battery power capacity, and accessibility to the internet, have an impact on the users' experience (Elias, 2011; Taleb and Sohrabi, 2012). The availability of synchronous and asynchronous communication tools are decisive in shaping communicative practices and fostering online interaction and collaboration (Gikas and Grant, 2013; Liaw et al., 2010). Social technology can promote backchannel conversation and help to facilitate the formation of an informal learning environment (Gikas and Grant, 2013; Wong, 2016).

The studies on mobile learning in Hong Kong have focussed mainly on the acceptance and attitudes of learners towards this learning mode. For example, So (2008) synthesised the perceptions of pre-service teachers on the use of mobile technologies. Lam et al. (2011) examined the readiness of university students to adopt mobile technologies for learning purposes. Wong (2014) investigated how university students perceived the use of mobile devices in learning mathematics. Also, Cheung (2015) carried out research on the engagement and satisfaction level of students on the implementation of mobile learning in language courses. These studies provided insights into the potentials of employing mobile technologies in curriculum and instruction.

Nursing education emphasises equipping students with competencies in knowledge, skills and attitudes in different areas (HKNC (The Nursing Council of Hong Kong), 2012). The multiple settings it involves (e.g. lecture hall, laboratory and clinical ward), and the high 
level of acuity it requires - together with the fast-paced development of technology and knowledge in the field - create demands on mobile learning which features a high level of mobility and flexibility (Kenny et al., 2009).

To ensure the effective delivery of mobile learning, the diverse needs of nursing students and teaching staff in terms of the device, content, and application have to be carefully considered. Anshari et al. (2016) reported the views of students that mobile learning needs to allow better flexibility for their learning beyond regular school hours. The functions supported by mobile devices should ease users' burden in carrying out tasks and enhance the accessibility of useful resources (Cacace et al., 2005). Also, Mettiäinen (2015) showed the desire of nursing teachers to have a mobile tool to support the supervision of students' clinical training in terms of learning and assessment, especially for those who were scattered around the region, making regular visits impossible.

However, relevant studies have also identified potential problems in practising mobile learning. Byrne-Davis et al. (2015) noted the concerns of medical students about the use of mobile technology in their learning, such as the availability of Wi-Fi access; potential theft or infection control; the appropriateness/convenience of using the devices in wards in front of the patients; the possibility of damaging or losing the devices; and the cost of buying the relevant apps or gadgets. Nestel et al. (2014) also point out that mobile-aided interaction may not be preferred by students in contacting faculty members.

\section{The FRAME model}

Koole's (2009) FRAME model is adopted in the present study to account for the factors that affect the delivery of mobile learning in the nursing discipline. The model covers the device, and learner and social aspects of mobile learning, and outlines the factors - device usability, interaction learning, and social technology - that affect the effective integration of these aspects.

Device usability is about how the functionalities of a mobile device enable learners to engage in cognitive tasks and how the device affects learners' psychological satisfaction. Important criteria of this aspect include portability, information availability, psychological comfort, and satisfaction. Portability refers to the ease for users of taking the device around; information availability concerns the accessibility, storage, and retrieval of learning resources; psychological comfort emphasises the reduction of users' cognitive load in performing tasks; and satisfaction is the users' experience and enjoyment in using the device (Koole, 2009).

Interaction learning synthesises learning and instructional theories, emphasising social constructivism with a particular focus on interactive patterns and the formation of learning communities. The interaction between learner-content, learner-teacher, and learner-learner are the major forms of stimulation in learning; while learning communities specifically focus on the collaboration among learners to achieve mutual goals (Koole, 2009).

Social technology addresses how mobile devices support communication and collaboration among individuals and systems. Device networking determines how good the connection is between users, systems, and information. System connectivity refers to the mobile programmes that facilitate the exchange of documents and information (Koole, 2009).

The FRAME model has been adopted widely in relevant studies (e.g. Kenny et al., 2009, 2010, 2012; Kumar et al., 2011; Parscal et al., 2012), and serves as a foundation for developing effective learning materials and teaching and learning strategies for mobile education. For example, Kenny et al. (2009) applied the model to evaluate the effectiveness of mobile learning in students' nursing practice in a Canadian college. In the study, device usability was perceived as satisfactory, despite the inadequate time 
AAOUJ 12,2

for students to fully master the technology; positive feedback was received on the aspect of interaction learning, with a particular focus on the enhancement of learner-content interaction; while the effect of social technology in fostering communication and collaboration remained unclear due to unstable connectivity and the hospital culture. Koole et al. (2010) used the model to assess the implementation of mobile learning in a master's degree programme at a Canadian university, and found that users' lack of familiarity with mobile technology led to a low rating in device usability; mobile access had no effect on the enhancement of interaction learning; and the positive attitude of students towards the potential of social technology was inconsistent with their actual preference of learning mode. Also, Kumar et al. (2011) examined the effect of mobile learning in a postgraduate diploma class of a clinical cardiology programme at an Indian university with the use of the model. Students reported a fair level of satisfaction in device usability, and expressed confidence in the effect of mobile devices on interaction learning.

The FRAME model has been applied in previous studies to identify the aspects where mobile learning yields a better performance, and the areas for further development, targeted at the improvement of learners' learning capacities or their communication. In the current research, this model is used as a framework to investigate the needs of students and their teacher in mobile learning in Hong Kong's nursing education.

Despite the relevant literature on the effectiveness of mobile learning and developing a mobile learning system, the studies evaluating the strengths and weaknesses of mobile learning for supporting tertiary education in Hong Kong have been largely underdeveloped; and they do not address the integration of such practice in nursing education - a field where mobile learning is highly desirable.

This study therefore aims at evaluating the implementation of mobile learning in Hong Kong's nursing education. In addition to analysing the students' and teacher's experiences in mobile learning using the FRAME model, this paper also discusses the pedagogical implications for the blending of mobile learning and nursing education.

\section{Research method}

Using a qualitative approach, this study aims to collect and analyse the views and suggestions of the students and teacher in a nursing course on the design and implementation of mobile learning. Apple iPad mini was proposed as the device for mobile learning, with a mobile app developed specially for supporting learning and teaching in a nursing course covering the concepts and skills related to health assessment.

The study included 20 out of the 180 Year 2 undergraduate students enroled in the nursing course "Health Assessment" at The Open University of Hong Kong, who were recruited using random sampling. Two focus group interviews, with ten students in each group, were conducted to collect information on learners' experiences and to stimulate suggestions on the instructional design of mobile learning. An in-depth individual interview with the course teacher was also conducted to collect opinions on mobile learning from the instructor's perspective. A teacher's insights are necessary for the evaluation of mobile learning effectiveness, since he/she plays a key role in designing the course and serves as the students' mentor and facilitates their engagement in mobile learning (Alrasheedi et al., 2015; Gikas and Grant, 2013).

The interviews were conducted in November 2014, with written consent sought from all the participants prior to the interviews. Structures based on the FRAME model, the interviews cover the aspects of device usability, interaction learning, and social technology. The participants were also asked about the features they desired in the mobile app. The interview data were transcribed and coded, and the key themes were identified using the FRAME model. Selected quotes from the participants were translated into English as shown in the next section. 


\section{Findings}

The students' and teacher's responses are presented below, following the FRAME model.

\section{Device usability}

Portability. The students regarded portability as a consideration for the choice of mobile devices for learning. They indicated their preference for a smaller size of device, which they could carry anywhere. Particularly in the practicum context, a device with a larger screen was not considered suitable for use. As noted by student "Ra":

It depends on where you are going to use them. It is really inconvenient to use an iPad in a ward.

Student "He" also mentioned the inconvenience of using an iPad in the practicum context:

Even if you are able to put it in your pocket, you would not do so. The staff [at the clinical venue] would criticise you if they found you using a mobile device during clinical hours.

The use of mobile devices enables students to store electronic learning materials on the devices and removes the inconvenience of carrying heavy printed textbooks when attending classes. This increases the flexibility of students' schedules, as they can participate in other activities before or after classes, without the burden of carrying books. Student "N" stated:

You would not want to carry a thick textbook around with you. But you can store an e-book in your mobile phone or tablet and go anywhere with it.

Student "Ch" indicated his use of different textbook versions in different contexts:

It is difficult to bring a hard copy textbook if you've got something else to do besides attending class. In this case, I would bring an iPad with the e-textbook pre-stored. But at home, I would use the hard copy.

Information availability. A mobile device can store information sources, such as textbooks, lecture materials, students' notes, and videos, which allows students to collect and access the information anywhere and anytime. Student "Ho" stated:

Some students would use their iPads to download [lecture notes]. It is quite convenient as we can jot notes directly onto the device.

The absence of relevant learning resources, however, makes it difficult to satisfy the just-in-time learning needs of students. The teacher said:

Not all relevant videos can be found online. Some videos contradict the textbook materials and contain errors. Some are too difficult, and may be provided for doctors in practice or postgraduate students. Students often get confused when searching for videos online by themselves.

Psychological comfort. The use of mobile devices can reduce students' cognitive load and enhance their speed in locating information. Student "N" indicated that the search function is important for him for learning. He stated:

When you search for some terms or words [in the textbook], you just press a button [on the device] and you can see where they appear in the whole book.

Satisfaction. Some students, who were still using printed materials, despite having the electronic version stored in their mobile devices, indicated the limitation of the user interface for effective reading and note-taking. Student "Ng" noted that:

I would still take notes on paper, because I cannot do two things at the same time on the device. I have to open an app to read the e-textbook and another app to take notes. Even if I can manage to use both apps together, the display on the device would be too small. 
AAOUJ

12,2

Thus, a larger screen size, despite being less portable, would be convenient for students, especially for reading. Student "Ri" said that he used his mobile phone for reading only when he had no other options:

The screen size of a mobile phone is really small. I use it for reading only when I have no other options. So usually I would study at home, using the PC with a larger screen.

\section{6}

\section{Interaction learning}

Learner-content interaction. Uncertainty about the reliability of internet sources is one of the major issues when students search for learning content online. As Student "He" stated:

The problem is that I am not sure if the sources are reliable. Everyone can upload a video on YouTube, even if the contents contain doubtful ideas. I view only those I feel are reliable, but I don't know whether they are really so. This is our concern.

The teacher responded to this issue by providing links to relevant reliable YouTube sources to students. She also pointed out that the nursing videos on the clinical procedures for health assessment need to be regularly updated to include the most recent procedures. Addressing this issue, she explained the budget problems with frequent updates and the difficulty in finding actors:

Because health assessment involves privacy issues, such as laying bare a performer's bosom and arms, it is difficult to find actors and it is much more costly [than hiring ordinary actors]. After the videos are filmed, frequent updates are still needed to follow the changes of practice in the real clinical setting.

Learner-teacher interaction. Students tend to ask the teacher questions individually face-to-face or through e-mails. Student "He" raised this issue:

It depends on the length of the question. Sometimes when I feel I cannot elaborate my question well through email, I ask the teacher face-to-face individually. Or I ask it before or after a lab session.

Student "Ho" said that he felt more comfortable in asking the teacher questions after reviewing the materials after class, and so he preferred sending e-mails. He said:

Before reviewing the materials, you don't know what to ask. Sometimes you know what you do not understand only after reviewing the materials at home. In that case, I would send emails [to ask the teacher].

The teacher, however, stated that she seldom uses e-mails to communicate with students, as she has found that they rarely check their mailboxes. For responding to individual questions, she would contact the students individually on the phone. She also utilises text messaging tools, such as WhatsApp or SMS, if the students do not answer the phone. She stated:

If [the problem] is not related to everyone, I would call the students on the phone [...] I would first try to use the telephone, and send an SMS if they did not pick it up.

Learner-learner interaction. The students would share learning materials online. Student "N" noted that:

We usually share the resources. For instance, the practical examination of 103 (i.e. the course "Fundamental Nursing Practice") requires students to perform certain skills in health assessment. We would share the steps of assessment to let our peers know how to perform them. 
Learning communities. Students enter into dialogues and collaborate in group projects with the use of messaging tools. As student "N" said:

After discussing face-to-face, we will work on different parts of a group project. If we have any questions, we would use WhatsApp [to communicate], and we usually use its audio recording feature [to send out voice messages].

Social technology

Device networking. The teacher pointed out that a network problem may limit the effectiveness of in-class activities using the mobile app, and mentioned an experience of failure in using a mobile polling system in class due to such a problem. She said:

The network connection was not that good at the time. It wasted a lot of time and students were discontented with that, as I could not finish teaching all the course materials on time.

System connectivity. The students utilised social media for information-sharing and exchanging skills. Student "He" noted:

We have a Facebook group to share learning materials. I believe that there are similar groups in other courses.

The teacher would also use the course learning management system for disseminating information and materials:

I would post what everyone needs to know on the OLE (i.e. the learning management system).

Tables I and II summarise the students' and teacher's views and suggestions for mobile learning.

Device usability

Portability

It is inconvenient to use a mobile device with a large screen in a ward

Using a mobile device during clinical hours will be criticised by staff

Storing materials in a mobile device can get rid of carrying thick textbooks, and increases the flexibility of the students' learning schedules

Information It is convenient to jot notes directly onto the device with the lecture notes

availability pre-downloaded to it

Psychological comfort Terms can be searched efficiently in the e-textbook on the mobile device

Satisfaction

The user interface has not been optimised to reduce the complexity in displaying text and taking notes simultaneously

The screen size of the device is too small which makes it unfit for reading and multitasking

Interaction learning

Learner-content

Learner-teacher

Learner-learner

Learning

communities

Social technology

System connectivity
Learner-content interaction is hampered by the uncertainty about the reliability of learning content online

Some students prefer asking the teacher questions individually face-to-face

Some students tend to ask teachers questions through e-mails after reviewing the materials after class

Learning resources are shared online among peers

Students enter into dialogues and collaborate in group projects with the use of messaging tools such as WhatsApp

Social media such as Facebook groups can be used to share learning materials
Table I. Summary of the students' views and suggestions on mobile learning 
AAOUJ 12,2

\section{8}

Device usability Information availability

Interaction learning Learner-content

Social technology

Table II.

Summary of the teacher's views and suggestions on mobile learning

Device networking
The absence of relevant online videos makes it difficult to satisfy the just-in-time learning needs of students

The nursing videos on the clinical procedures need to be regularly updated. Online videos may contradict textbook materials and contain errors; and most of them are not suitable for undergraduate studies and the local context in Hong Kong Reliable learning content online can be collected by teachers and provided to students to resolve the students' concern about the reliability of online sources

Some students rarely check their mailboxes

Students can be contacted separately on the phone for responding to their individual questions. Text messaging tools can also be used if needed

The effectiveness of in-class activities using the mobile app is largely dependent on the quality of the network connection

System connectivity The learning management system can be used for disseminating information and materials that everyone needs to know

\section{Desired features of the mobile app}

Learning tool. Additional features of the mobile app were suggested by the students and teacher, including learning tools such as a medical dictionary. Student "Y" noted:

I would like to see the availability of a medical dictionary that we can use to search for information about diseases. The lecture notes do not include sufficient detail for us to have a clear idea about the exact symptoms of a disease. We need to search for them online, and there is often too much information and complications. It would be great if there was an app we can use to search easily for the relevant information.

Multimedia materials. The students indicated a wish to see the learning contents presented using videos or animations. Student "Ho" said:

When I do revision, I always try to visualise the content. I think it is good to have animations illustrating the aetiology of certain diseases.

Student "Ho" also suggested using multimedia materials to present the difficult concepts, such as the electrocardiography (ECG) rhythm, as this would help in interpreting it. He said:

There are many variations in ECG rhythm, and the variations can be tricky. If the rhythm can be presented using the multimedia technology, it would facilitate my interpretation.

Online forum. The teacher recommended setting up an online forum which can be accessed through the mobile app to enhance social interaction and allow her to identify students' learning difficulties. She noted:

To facilitate discussion and interaction, we could set up an online forum. I could post questions on the forum, with students being required to spend some time looking at the questions and providing feedback. I could also see through students' feedback if there are any problems that have to be resolved.

Student response system. The teacher also suggested using a student response system with Q\&A or exercise functions for in-class activities. This feature can potentially promote inclass interaction between students and the teacher, which could be challenging in a conventional lecture setting with a large number of students. She pointed out that she could identify students' mistakes and common pitfalls through the Q\&A and exercises, 
and provide suggestions to students individually or address the problems during the class. She said:

[By introducing this feature,] I would not only talk in class. Students could do practice and revisions using the app. I could know the performance of students on the exercises, and respond to them promptly. I could provide suggestions for their learning or share the suggestions in class.

\section{Mobile learning in nursing education}

The in-class Q\&A can help students to stay focused, as they have to do the exercise on the app. It is impossible for it to be done by neighbouring peers, as everyone has to work with their own device.

In addition, the Q\&A function can serve as an attendance recording tool for class administration. As mentioned by the teacher:

I could tell if you attended the lecture the moment you respond to the Q\&A. Besides, this can also motivate students to come to class, as we have a minimum attendance requirement.

Table III summarises the students' and teacher's desired features of the mobile app.

\section{Discussion}

The effectiveness of mobile learning in nursing education following the FRAME model

Device usability. Consistent with relevant studies (e.g. Kukulska-Hulme, 2005; Nestel et al., 2014), the findings in this study have shown that the use of mobile devices reduced students' physical burden of carrying textbooks and enhanced their accessibility to learning materials. Also similar to the findings of Cacace et al. (2005), it was found that the "search" function of mobile devices was valued by the nursing students, as it relieved their cognitive load by speeding up their process of performing time-consuming tasks such as searching for terms and retrieving particular content. The criteria of portability, information availability, and psychological comfort were fulfilled to a certain extent.

The advantage of portability is, however, countered by the hospital culture and policies that preclude the use of mobile devices during clinical hours; and a similar situation was reported in the Canadian context (Kenny et al., 2009). The students also raised concerns over the unfriendly user interface of the mobile app that complicated the procedure of reading texts and jotting notes simultaneously. Consistent with the research of Woody et al. (2010),

The students' desired features

Learning tool A medical dictionary is desirable for providing more details about the symptoms of diseases and easy searching for relevant information

Multimedia materials When doing revision, it is more effective to visualise the content and have animations illustrating the aetiology of certain diseases

As there are many variations in electrocardiography rhythm and they can be tricky, presenting the difficult concepts using multimedia materials can facilitate the interpretation of the rhythm

The teacher's desired features

Online forum An online forum can facilitate discussion and interaction among students. Teachers can also identify students' problems from their responses in the forum

Student response system A student responses system can allow teachers to provide Q\&A or exercises for in-class activities. The teachers can know the performance of students on the exercises and respond to them promptly. Suggestions for students' learning can also be provided to individual students or to the whole class The in-class Q\&A can help students to stay focused during the lectures Teachers can be aware of students' attendance when they respond to the Q\&A

Table III.

Summary of the students' and teacher's desired features of the mobile app 
AAOUJ

12,2

180

some students preferred the readability of printed materials despite the availability of electronic information.

To raise the level of satisfaction among learners, the functionality of the app, user interface, and screen design have to be further optimised to support multitasking and better readability.

Interaction learning. Contrary to the findings of Kenny et al. (2009) and Kumar et al. (2011), the enhancement in learner-content interaction was unclear in this study. Some of the online resources on clinical procedures and nursing knowledge, which were found to be imprecise, narrow, and outdated, reduced the applicability of these materials in mobile learning. These findings echo the factors stated in the research work of Leacock and Nesbit (2007) that affect the quality of learning resources, such as content quality, presentation design, and standards compliance.

The study, nevertheless, has shown that the availability of synchronous and asynchronous communication tools can enhance online interaction and collaboration between learners (Au et al., 2017; Gikas and Grant, 2013; Liaw et al., 2010). In terms of learner-teacher interaction, it was found that the conventional communication practices, such as face-to-face interaction and e-mails, were more often employed; mobile texting was a supplementary method when conventional practice failed. Learner-learner interaction and the formation of learning communities are facilitated by mobile applications, e.g. WhatsApp. Instant messaging has been perceived by students as a personalised and timely way to receive information (Traxler, 2007). Also, Rambe and Bere (2013) found that the students preferred mobile instant messaging to traditional classroom interaction because of its anonymity, flexibility, and affordances for personal reflection.

Social technology. In this research, the teacher mentioned an unpleasant class experience in relation to students' failure to use the polling system in the mobile app which was intended to promote interactions and support in-class learning. The effectiveness of running the mobile app directly affects the implementation of interactive learning activities, but the stability of the app depends considerably on high bandwidth on the wireless network. As Gikas and Grant (2013) suggest, social media and Web 2.0 tools open up opportunities for students to engage in creating collaborative content. It was found that the availability of information exchange tools enhanced system connectivity and enabled the students to share learning materials with each other. The teacher also utilised the functions of the learning management system to disseminate information and materials to a mass group of students.

The potentials of and constraints on the blending of mobile learning and nursing education Enhancement of learning flexibility and effectiveness. In this study, the students indicated their preference for accessing the materials in an electronic version for mobility, which highlights the importance of device portability in considering the various learning settings of nursing students. Despite the students' concern over the reliability of online learning resources, their desire for encyclopaedic information and multimedia materials with visualised content on medical knowledge were observed, illustrating the potential of mobile technologies for enhancing learning effectiveness. As Sanchez and Goolsbee (2010) suggested, the effective display of information on mobile devices may have an impact on learning in terms of the recall and reconstruction of information. Thus, the device design and diversity of mobile functions have the potential to be further optimised to support the dynamic learning environment and rapid development in nursing education.

Perceptual differences between students and the teacher. In the interviews, the students focussed little on the large-group interaction for learning. Relevant studies (e.g. Cheung, 2015; Li and Wong, 2014) have also pointed out that students were not interested in participating in online discussion forums. They tended to ask the teacher questions individually, and use social media mainly for sharing materials and instant messaging for 
completing group assignments. On the other hand, the teacher acknowledged the potential of mobile technologies (e.g. the development of online forums and student response systems) for promoting class interaction, and planned to include this element in the practice of mobile learning.

When asked about the desired features of the mobile app, the students highlighted the need for more supplementary learning materials to enhance their understanding of the subject, while the teacher focussed on testing the knowledge and monitoring the learning behaviours of students. It appears that there is a perceptual difference between students and the teacher in their expectations of mobile technology for supporting learning and communication. The dialogue between the two parties would be helpful in achieving a mutual agreement on mobile learning (Wang et al., 2009).

\section{Conclusion}

In summary, this paper has presented the views and expectations of students and their teacher on the practice of mobile learning, and evaluated the strengths and limitations of mobile technologies in supporting nursing education. The findings showed that the aspects of device usability, interaction learning, and social technology as suggested in the FRAME model were partly fulfilled. Despite the potential of using mobile technologies in nursing education, attention should be paid to the perceptual differences between students and the teacher on the nature and functions of mobile learning. For a university preparing for the delivery of mobile learning, this possible gap has to be bridged to ensure that what is provided fits the needs of both user groups, so that they are more ready and willing to engage in mobile learning.

This research also has implications for advancing the theoretical foundations of mobile learning. Despite related models and frameworks indicating the general considerations, they have yet to adequately address the variation in different user groups and subject areas. Further work on this aspect would be helpful for informing the delivery of mobile learning that, as this study has suggested, is context- and subject-dependent in nature.

\section{References}

Alrasheedi, M., Capretz, L.F. and Raza, A. (2015), "Instructor perspectives of mobile learning platform: an empirical study", International Journal of Computer Science and Information Technology, Vol. 7 No. 3, pp. 27-40.

Anshari, M., Alas, Y., Yunus, N., Sabtu, N.I. and Hamid, M.H. (2016), "Online learning: trends, issues, and challenges in the big data era", Journal of e-Learning and Knowledge Society, Vol. 12 No. 1, pp. 121-134.

$\mathrm{Au}$, O.T.S., Li, K.C. and Wong, B.T.M. (2017), "Student persistence in open and distance learning: a case in Hong Kong", The 31st Annual Conference of the Asian Association of Open Universities (AAOU), 27-29 September, Yogyakarta.

Baker, A., Dede, C. and Evans, J. (2014), "The 8 essentials for mobile learning success in education", available at: www.qualcomm.com/media/documents/files/the-8-essentials-for-mobile-learningsuccess-in-education.pdf (accessed 29 November 2016).

Byrne-Davis, L., Dexter, H., Hart, J., Cappelli, T., Byrne, G., Sampson, I., Mooney, J. and Lumsden, C. (2015), "Just-in-time research: a call to arms for research into mobile technologies in higher education”, Research in Learning Technology, Vol. 23 No. 1, available at: http://dx.doi.org/10. 3402/rlt.v23.25653 (accessed 29 November 2016).

Cacace, F., Cinque, M., Crudele, M., Iannello, G. and Venditti, M. (2005), "The impact of innovation in medical and nursing training: a hospital information system for students accessible through mobile devices", in Attewell, J. and Savill-Smith, C. (Eds), Mobile Learning Anytime Everywhere, Learning and Skills Development Agency, London, pp. 47-52. 
AAOUJ 12,2
Cheung, S.K.S. (2015), “A case study on the students' attitude and acceptance of mobile learning", in Li, K.C., Wong, T.L., Cheung, S.K.S., Lam, J. and Ng, K.K. (Eds), Technology in Education: Transforming Educational Practices with Technology, Springer, Berlin, pp. 45-54.

Elias, T. (2011), "Universal instructional design principles for mobile learning", The International Review of Research in Open and Distributed Learning, Vol. 12 No. 2, pp. 143-156.

Evans, C. (2008), "The effectiveness of m-learning in the form of podcast revision lectures in higher education", Computers \& Education, Vol. 50 No. 2, pp. 491-498.

Gikas, J. and Grant, M.M. (2013), "Mobile computing devices in higher education: student perspectives on learning with cellphones, smartphones \& social media", Internet and Higher Education, Vol. 19, pp. 18-26.

HKNC (The Nursing Council of Hong Kong) (2012), "Core-competencies for registered nurses (general)", available at: www.nchk.org.hk/filemanager/en/pdf/core_comp_english.pdf (accessed 29 November 2016).

Kenny, R.F., Park, C.L., Van Neste-Kenny, J.M.C. and Burton, P.A. (2010), "Mobile self-efficacy in Canadian nursing education programs", paper presented at the 9th World Conference on Mobile Learning (mLearn), Valletta, 19-22 October, available at: http://hdl.handle.net/2149/2767 (accessed 29 November 2016).

Kenny, R.F., Park, C.L., Van Neste-Kenny, J.M.C., Burton, P. and Qayyum, A. (2012), "Using self-efficacy to assess the readiness of nursing educators and students for mobile learning", International Review of Research in Open and Distance Learning, Vol. 13 No. 3, pp. 277-296.

Kenny, R.F., Van Neste-Kenny, J.M.C., Park, C.L., Burton, P.A. and Meiers, J. (2009), "Mobile learning in nursing practice education: applying Koole's FRAME model”, Journal of Distance Education, Vol. 23 No. 3, pp. 75-96.

Koole, M.L. (2009), "A model for framing mobile learning", in Ally, M. (Ed.), Mobile Learning: Transforming the Delivery of Education and Training, AU Press, Athabasca, pp. 25-47.

Koole, M.L., McQuilkin, J.L. and Ally, M. (2010), "Mobile learning in distance education: utility or futility?", International Journal of E-Learning \& Distance Education, Vol. 24 No. 2, pp. 59-82.

Kukulska-Hulme, A. (2005), "Introduction", in Kukulska-Hulme, A. and Traxler, J. (Eds), Mobile Learning: A Handbook for Educators and Trainers, Routledge, London and New York, NY, pp. 1-6.

Kukulska-Hulme, A. and Traxler, J. (2005), "Mobile teaching and learning”, in Kukulska-Hulme, A. and Traxler, J. (Eds), Mobile Learning: A Handbook for Educators and Trainers, Routledge, London and New York, NY, pp. 25-44.

Kumar, L.S., Jamatia, B., Aggarwal, A.K. and Kannan, S. (2011), "Mobile device intervention for student support services in distance education context - FRAME model perspective", European Journal of Open, Distance and E-Learning, Vol. 2011 No. 2, available at: www.eurodl.org/?p=archives\& year $=2011 \&$ halfyear $=2 \&$ article $=447$ (accessed 29 November 2016).

Lam, P., Wong, K., Cheng, R., Ho, E. and Yuen, S. (2011), “Changes in student mobile learning readiness - comparison of survey data collected over a nine-month period", Proceedings of Global Learn, Association for the Advancement of Computing in Education, Melbourne, pp. 180-189.

Leacock, T.L. and Nesbit, J.C. (2007), "A framework for evaluating the quality of multimedia learning resources”, Educational Technology \& Society, Vol. 10 No. 2, pp. 44-59.

Lee, J.K.L. and Tsang, E.Y.M. (2006), "Mobile learning support in patient care and clinical nursing education", paper presented at the International Conference on ICT in Teaching and Learning (ICT), 10-11 July, Hong Kong.

Li, K.C. and Wong, B.T.M. (2014), "Readiness development of open educational resources in Hong Kong", International Journal of Continuing Education and Lifelong Learning, Vol. 7 No. 1, pp. 119-137.

Li, K.C., Lee, L.Y.K., Wong, S.L., Yau, I.S.Y. and Wong, B.T.M. (2015), "Mobile learning in nursing education: Preference and readiness of nursing students", The 2nd International Conference on Open and Flexible Education (ICOFE), Hong Kong, 16-17 July, pp. 313-323. 
Liaw, S.S., Hatala, M. and Huang, H.M. (2010), "Investigating acceptance toward mobile learning to assist individual knowledge management: based on activity theory approach", Computers \& Education, Vol. 54 No. 2, pp. 446-454.

Mettiäinen, S. (2015), "Electronic assessment and feedback tool in supervision of nursing students during clinical training", The Electronic Journal of e-Learning, Vol. 13 No. 1, pp. $42-55$.

\section{Mobile learning in nursing education} medical school: feasibility and educational benefits in campus and clinical settings", Journal of Biomedical Education, Vol. 2014, pp. 1-8, available at: http://dx.doi.org/10.1155/2014/ 412786 (accessed 29 November 2016).

Parscal, T., Sherman, K., Heitner, K. and Lucas, G. (2012), "A new model to measure student engagement with a mobile learning tool integrating CoI and FRAME", Proceedings of Global TIME, Association for the Advancement of Computing in Education, pp. 31-37.

Rambe, P. and Bere, A. (2013), "Using mobile instant messaging to leverage learner participation and transform pedagogy at a South African University of Technology", British Journal of Educational Technology, Vol. 44 No. 4, pp. 544-561.

Sanchez, C.A. and Goolsbee, J.Z. (2010), "Character size and reading to remember from small displays", Computers \& Education, Vol. 55 No. 3, pp. 1056-1062.

So, S. (2008), "A study on the acceptance of mobile phones for teaching and learning with a group of pre-service teachers in Hong Kong", Journal of Educational Technology Development and Exchange, Vol. 1 No. 1, pp. 81-92.

Taleb, Z. and Sohrabi, A. (2012), "Learning on the move: the use of mobile technology to support learning for university students", Procedia - Social and Behavioral Sciences, Vol. 69, pp. 1102-1109.

Traxler, J. (2009), "Current state of mobile learning”, in Ally, M. (Ed.), Mobile Learning: Transforming the Delivery of Education and Training, AU Press, Athabasca, pp. 9-24.

Uzunboylu, H. and Ozdamli, F. (2011), "Teacher perception for m-learning: scale development and teachers' perceptions", Journal of Computer Assisted Learning, Vol. 27 No. 6, pp. 544-556.

Wang, M., Shen, R., Novak, D. and Pan, X. (2009), "The impact of mobile learning on students' learning behaviours and performance: report from a large blended classroom", British Journal of Educational Technology, Vol. 40 No. 4, pp. 673-695.

Wong, B.T.M. (2016), "Factors leading to effective teaching of MOOCs", AAOU Journal, Vol. 11 No. 1, pp. 105-118.

Wong, G.K.W. (2014), "Engaging students using their own mobile devices for learning mathematics in classroom discourse: a case study in Hong Kong", International Journal of Mobile Learning and Organisation, Vol. 8 No. 2, pp. 143-165.

Woody, W.D., Daniel, D.B. and Baker, C.A. (2010), "E-books or textbooks: students prefer textbooks", Computers \& Education, Vol. 55 No. 3, pp. 945-948.

\section{Corresponding author}

Billy Tak Ming Wong can be contacted at: tamiwong@ouhk.edu.hk

For instructions on how to order reprints of this article, please visit our website:

www.emeraldgrouppublishing.com/licensing/reprints.htm

Or contact us for further details: permissions@emeraldinsight.com 